\title{
Resiliencia y trayectoria de las mujeres garífunas y afrodescendientes en Centroamérica, particularmente Guatemala
}

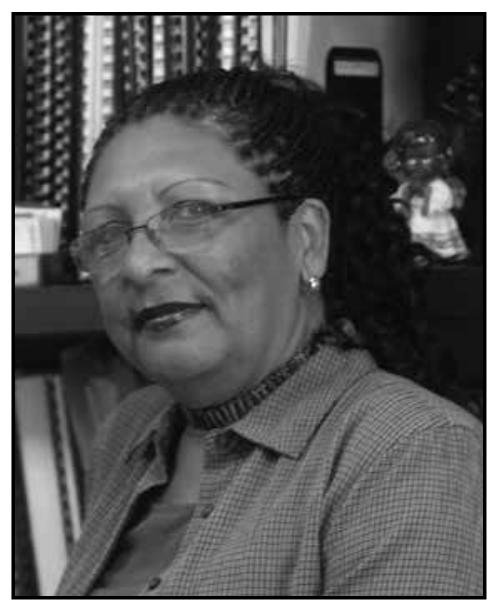

\begin{abstract}
Lo nuestro no es alegría, es resiliencia, nace de nuestro sufrimiento, de nuestra lucha cotidiana y de la invisibilidad a la que nos someten como pueblo y como cultura afrodescendiente.
\end{abstract}

Memoria de una hija de Oshun

Alta Hooker Blandford ${ }^{1}$

\begin{abstract}
$\mathrm{Q}$ uiero empezar esta presentación, felicitando a la Universidad de San Carlos Guatemala (USAC) por la aprobación de la Cátedra: "Mujeres Garífunas y Afrodescendientes del Instituto Universitario de la Mujer", por ser un espacio vital donde se propiciará el diálogo, el intercambio de experiencias, la concertación y el consenso, en la búsqueda de poder construir instrumentos dirigidos a la reducción de la discriminación, el racismo institucionalizado, la marginación y por ende ver el desarrollo de esta población desde otra mirada.
\end{abstract}

Es también la celebración a las mujeres garífunas y afrodescendientes que han luchado e incidido para que este sueño de la cátedra fuese una realidad. Los garífunas y afrodescendientes (mujeres y hombres) en Centroamérica, tenemos un pasado en común, nuestros antepasados vinieron a América en los siglos XV y XVI en contra de su voluntad, traídos por barcos negreros ingleses, españoles, portugueses, holandeses y franceses a las colonias como mano de obra para producir la riqueza de estos países.

Esta trayectoria emprendida por nuestros antepasados desde la madre tierra, África, a lugares desconocidos y hostiles, ha significado separación de las familias, pérdida de derechos, autodeterminación, tierra y territorio. Ha significado luchar por la sobrevivencia, la defensa de la cultura, la identidad y el orgullo de ser negras y negros. Ha significado resistencia, sobrevivencia, lucha persistente por la libertad y el derecho a dirigir nuestro propio destino. Ha significado resiliencia.

Hablando del pueblo garífuna y afrodescendiente, podemos decir que somos parte de la población más vulnerable de América, privados en su mayoría al acceso a la tierra y territorio: a sus beneficios provenientes, al derecho a la autodeterminación, a bienes y servicios básicos pertinentes y de calidad como salud, justicia, servicios comunitarios y educación, impidiéndonos el goce pleno de la ciudadanía y por ende al desarrollo con identidad. Como garífunas y afrodescendientes, representamos una quinta parte del total de la población de la región y junto con los pueblos indígenas, el segmento más pobre del continente.

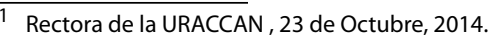


Esta situación se agrava con los proyectos que se desarrollan en nuestros territorios sin la correspondiente consulta del consentimiento previo, libre e informado; la falta de oportunidad a empleo de calidad, la ausencia de políticas públicas culturalmente pertinentes y el poco conocimiento y aplicación de nuestros derechos. Los pueblos garífunas y afrodescendientes de América compartimos una historia común: orígenes, cultura e identidad. Afrontamos problemas políticos, económicos y culturales, cuyas características centrales han sido la discriminación, los nuevos matices de racismo institucionalizados, marginación y exclusión que invisibiliza nuestras propuestas de desarrollo propio.

En el caso del pueblo garífuna ${ }^{2}$ el compañero Roy Cayetano, del Consejo Nacional Garífuna en Belice, compartió con nosotros elementos sobre esta población. Reflexionó, que en el año 1635 un barco esclavista naufragó cerca de la costa de la isla de San Vicente y que los africanos que venían a bordo fueron liberados y acogidos por los indígenas nativos.

Estos africanos fueron asimilados por los integrantes de la comunidad y sus hijos e hijas integrados a la sociedad, hablando el idioma, viviendo la cultura, compartiendo la espiritualidad. Otros negros escapando de la esclavitud también de territorios aledaños, continuamente se integraban a la isla y de la misma manera eran absorbidos por la comunidad garífuna, conocidos también como calinagos.

Los habitantes de la isla de San Vicente en ese entonces eran amerindios, una mezcla de caribes y arawaks. Los arawaks, vivieron y poblaron América del norte y del sur y con el tiempo se expandieron sobre los ríos, llegando eventualmente a las islas del Caribe hasta las Bahamas. Cuenta la historia que la expansión de los arawaks quedó corta con la llegada de Cristóbal Colón en 1492. Esta mezcla de población fue conocida como los Caribes Negros, quienes se identificaron como garinagos o garífunas, resultado de dos históricos viajes: La ruta de esclavos desde África y la migración de América del Sur de los arawaks/caribes.

Uno de los aspectos que siempre sale a relucir en las actividades llevadas a cabo entre garífunas y afrodescendientes es que a pesar de todos los inten-

\footnotetext{
2 Fragmentos de la participación del Sr. Roy Cayetano del Nacional Garífuna Council en Belize, en el primer Simposium Internacional de las cultura Creole y Garífuna, 22 al 24 de Octubre 2010.
}

tos de captura, ellos lograron resistir la esclavitud luchando y defendiendo sus derechos a su tierra y territorio en las guerras del Caribe bajo el liderazgo de Joseph Chatoyer. Después de la muerte de Chatoyer y la destrucción de sus canoas, fincas y ganados a mano de los ingleses, fueron perseguidos y encarcelados en la isla de Balliceaux entre julio de 1796 y el 11 de marzo de 1797.

De los 4,338 que fueron hechos prisioneros en Balliceaux, la mitad aproximadamente murieron. El 11 de marzo, 1797, los 2,248 que sobrevivieron, fueron embarcados en 12 navíos y llevados a destino desconocido. De los sobrevivientes, 2,026 que fueron embarcados a Balliceaux, lograron llegar a Roatán y dejados ahí por los ingleses con alguna provisión. Al quedar sin provisiones, tuvieron que depender de ellos mismos para sobrevivir en condiciones sumamente difíciles, continuando después algunos de esta población para desplazarse a Guatemala y Nicaragua.

"Como consecuencia de las circunstancias del racismo y la discriminación, estas comunidades garífunas y afrodescendientes han sufrido una serie de privaciones en el alcance de sus derechos humanos, en especial los derechos políticos, económicos, sociales y culturales" (Rangel, 2005).

Debido a este trasfondo histórico fuimos creando resiliencia, entendida actualmente como la capacidad de superar perturbaciones materiales o emocionales. La resiliencia nos ofrece una nueva opción, una nueva mirada para entender y conceptualizar ese trauma vivido; además de la posibilidad de enriquecer y potenciar la habilidad natural que tenemos los garífunas y afrodescendientes para afrontar, resistir, e incluso crecer a partir de estas vivencias. Esto que parece sencillo hoy, es muy difícil de hacer cuando nacemos y crecemos en medio de una realidad jerarquizada culturalmente, con desventajas sociales, como sucede con el racismo estructural, el que se erige con las instituciones ciudadanas como cosa normal y aceptada.

Dentro de este marco las mujeres garífunas y afrodescendientes, han venido desempeñando un papel muy importante en el proceso de trabajar y luchar por el reconocimiento de los derechos individuales y colectivos de esta población, al mismo tiempo de continuar con la transmisión y revitalización de su cultura a nivel local, nacional e internacional. Estos esfuerzos han tenido resultados positivos en los espacios locales, nacionales 
e internacionales a como se ha reflejado en los tratados y convenios internacionales entre algunos ejemplos, el reconocimiento de las Naciones Unidas a la lengua, danza y música garífuna, como bien inmaterial de la Humanidad en noviembre del 2008, compartido con los países de Belice, Guatemala y Nicaragua. De la misma manera la Asamblea Nacional de Nicaragua, aprobó en el año 2014 la Ley de Declaración de la cultura garífuna como patrimonio cultural inmaterial de la nación.

\section{Cosmovisión y manera de ver el mundo del pueblo garífuna}

La historia compartida de la población garífuna y afrodescendiente de resistencia y resiliencia y en este caso especial las mujeres, ha tenido mucho qué ver con la manera de organización y de ver el mundo. Cayetano también planteó que la cosmovisión garífuna se puede entender desde el "Au bun, Amürü nu” que significa, "Tu para mí y yo para tî".

Esto significa que lo más importante no es contar con el gran excedente económico, lo importante es la vida en comunidad, el compartir y acompañar el quehacer comunitario, el diálogo para el consenso y la toma de decisiones desde la colectividad, el crecer y caminar juntos hacia el Buen Vivir/Well Being.

Esta manera de ver el mundo tiene mucho que ver con la cosmovisión del pueblo indígena miskitu, cuya práctica ancestral de organización comunitaria se fundamenta también en el (Pana-Pana) "tu para mí y yo para ti”, que se entiende como una manera de compartir y velar por el bienestar de cada uno, donde se comparte el quehacer comunitario, donde se siembra y canta al trabajar las parcelas de manera colectiva para el bien común.

En la cultura garífuna y afrodescendiente, las mujeres desempeñan un papel fundamental y destacado en la sociedad, son las principales transmisoras de la cultura, de generación a generación, mediante narraciones orales, cantos, juegos, rituales, con la finalidad de conservar el idioma, la espiritualidad, las creencias, la música, el baile y demás tradiciones. Son las que toman las principales decisiones en la comunidad y responsables de la salud integral de la familia mediante la práctica de la medicina tradicional ancestral.
La vida de la población garífuna y afrodescendiente se fundamenta en la espiritualidad. Los ancestros son convocados para acompañar las actividades importantes de la comunidad, para asegurar la siembra y la cosecha, para la sanación de las personas, el cuido de nuestras hijas e hijos, en el esfuerzo de mantener limpia la comunidad de los malos espíritus, que con frecuencia tratan de apoderarse de nuestros entornos. Los ancestros son convocados a acompañar las actividades de negociación y consenso que se realizan desde las redes de mujeres garífunas y afrodescendientes en la búsqueda de mantener la armonía y el equilibrio del medio natural y social desde la concertación.

Cuidan la madre tierra con normativas comunales propias, hechas por el consenso comunitario dirigidas a cuidarla y protegerla por sentirse parte de ella y que de ella viven. Cuidan y protegen a la comunidad como parte de una gran familia fundamentándose en la colectividad, donde el comunitarismo es más importante que los intereses personales. La vida de la población garífuna y afrodescendiente, se refleja en su manera de compartir en la comunidad que va más allá del canto y la danza, es realmente ver la vida desde los ojos de estos pueblos. Esto significa que la cultura es la filosofía de vida de nuestros pueblos y que debe transversalizar todo el proceso de desarrollo. Que se fundamenta en la armonía y el equilibro entre todos los componentes del entorno.

Si es así, el desarrollo del pueblo garífuna y afrodescendiente debe verse con otros ojos, desde otra mirada. Debe fundamentarse en la cosmovisión desde nuestros pueblos, articulado con las bondades de la cultura dominante que se necesita adoptar en el proceso de avanzar en el camino del bienestar. Esto hace necesario que el papel de las universidades en este contexto, sea el de acompañar a los diferentes pueblos, y en lo específico a las mujeres garífunas y afrodescendientes, a rescatar su visibilidad desde su propia realidad y necesidad, construyendo instrumentos para que puedan ser las principales investigadoras en el proceso de sistematizar nuestras historias, experiencias y a reconocer nuestras buenas prácticas para avanzar en el camino del desarrollo.

Apoyarlas en el diseño de sus propios materiales educativos fundamentados en el aprender a leer y escribir en su propia lengua y a construir el nuevo conocimiento desde su propia realidad e historia. Abrir espacios de diálogo, donde puedan hacer 
visible su cultura, más allá de los bailes y comida; sino desde los aspectos que los identifican como pueblos, desde su propia filosofía de vida, sin que tengan que sentir vergüenza.

Esta situación de las mujeres garífunas, no es ajena al de las otras mujeres de las comunidades afrodescendientes que ante la globalización, están en la lucha para ocupar todos los espacios posibles, especialmente en el ámbito familiar y comunitario con la finalidad de mantener la cosmovisión y las prácticas culturales de nuestros pueblos, mediante la utilización de mecanismos, siendo la resiliencia la forma que actualmente más ayuda a la pervivencia de la cultura y la convivencia pacífica. La resiliencia nos ayuda a confrontar las dificultades, a emprender acciones positivas, a crecer y a fortalecernos como garífunas y afrodescendientes en tantas circunstancias adversas que existen para nuestros pueblos.

El Decenio Internacional de los Afrodescendientes (1 de Enero del 2015 a 31 de Diciembre del 2024) bajo el lema: "Reconocimiento, Justicia y Desarrollo", es una oportunidad para la comunidad garífuna y afrodescendiente, especialmente para las mujeres en la unificación de esfuerzos y realizar una agenda conjunta como pueblo, entre sus organizaciones y con el Estado para impulsar acciones en pro del desarrollo socioeconómico y cultural mediante colaboraciones estratégicas, así como la adopción de políticas y programas por parte del Estado que permita el desarrollo con identidad de nuestros pueblos. En este proceso, la universidad juega un papel fundamental de acompañamiento a los pueblos garífunas y afrodescendientes en la elaboración de sus propuestas y es su preparación con elementos para la negociación y diálogo.

En este contexto es necesario ir profundizando en el abordaje intercultural como un proceso de lucha en contra de la discriminación y la invisibilización. El abordaje de la interculturalidad, necesita que las diferentes culturas estén en permanente intercambio y diálogo, dirigido a que haya relaciones entre las personas y las colectividades, conocimientos y prácticas culturalmente diferentes. De la misma manera necesita intercambios constantes y negociaciones que permitan construir espacios de diálogo y asociación entre seres, saberes y prácticas distintas.
La interculturalidad debe visibilizar los valores y la riqueza espiritual de las prácticas tradicionales y de las filosofías y conceptos de los diferentes pueblos, aspectos fundamentales para el mantenimiento y el equilibrio armónico del ser humano con su medio ambiente. Quiero terminar con un pensamiento de Enrique Camargo Manuel, en visiones Indígenas de la descentralización: Una mirada guaraní. Reflexionó que la vida de las personas en su comunidad se desarrolla con el ejercicio pleno de sus prácticas culturales vigentes, y que muchas veces están totalmente alejadas de las problemáticas nacionales, donde los indicadores económicos expresados en cifras y los resultados exitosos de los proyectos de desarrollo, demostrados en porcentajes y coberturas, no tienen mucho sentido.

En cambio, la existencia de suficiente espacio para el cultivo, la libertad para conducir el desarrollo comunitario como producto del consenso interno, el formar parte de una gran familia compartiendo un determinado territorio, eso sí da sentido a la vida y a la pertenencia de una colectividad con identidad propia, idioma y práctica de valores culturales milenarios. El pensamiento de Camargo es fundamental para tener ciudadanía. Entendida la ciudadanía en un mundo multicultural y pluricultural, a tener derecho a mantener diferencias culturales en la esfera pública: derechos como hacer uso de la lengua propia en espacios privados y públicos, y poder debatir con ellas sin tener que sentir vergüenza; derecho a mantener ciertas formas propias de practicar la justicia; derecho a los conocimientos tradicionales, que Buyeis, Bush Women and Bush Men tengan las mismas oportunidades y reconocimientos que los especialistas de la medicina occidental y que nuestra educación realmente haga visible la verdadera historia de nuestros pueblos, para que podamos sentirnos orgullosos de nuestros propios héroes y heroínas.

Una vez más deseo felicitar a la Universidad de San Carlos de Guatemala, por la aprobación de esta Cátedra: "Mujeres Garífunas y Afrodescendientes del Instituto Universitario de la Mujer" y a las mujeres garífunas y afrodescendientes por su persistencia en su lucha, por su visibilidad y haber hecho posible este peldaño más en su andar.

Muchas bendiciones y muchas gracias. 